\title{
PERAN STRATEGIS KEWIRAUSAHAAN DALAM MENDUKUNG KEBIJAKAN FOUR TRACK STRATEGY DI INDONESIA
}

\author{
Paiman Eko Prasetyo \\ Universitas Negeri Semarang \\ pekoprasetyo@mail.unnes.ac.id
}

\begin{abstract}
The purpose of this study is to explain the strategic role in overcoming major development problems. The research method used is a literature review with the main variable entrepreneurial strategic role. The data as empirical evidence in this article is taken from a literature review of relevant research results conducted by the previous author and data from the Global Entrepreneurship Monitor (GEM). The results of research that show a good Four Path Strategy (FTS) policy that is able to improve the quality of the economy, finance, finance and distribution inequality only with a policy strategy that is oriented towards entrepreneurship and innovation that is able to increase industrial capacity. If the policy (FTS) is not entrepreneurial oriented and capacity building, then the policy will be more likely to fail.
\end{abstract}

Keywords: economic growth, growth, poverty, inequality, entrepreneurship, industrial capacity, economic development

\section{PENDAHULUAN}

Tujuan kebijakan Four Track Strategy (FTS) adalah strategi kebijakan pemerintah Indonesia dalam bidang ekonomi yang diarahkan untuk mendorong pertumbuhan ekonomi guna mengurangi pengangguran, kemiskinan dan ketimpangan distribusi pendapatan. Pada masa pemerintahan Presiden SBY, kebijakan tersebut lebih difokuskan hanya pada tiga hal saja yang lebih dikenal dengan Triple Track Strategy (TTS), yakni pro growth, pro poor dan pro job. Sedangkan, pada masa pemerintahan Presiden Jokowi, dengan Nawa Citanya lebih dikenal sebagai FTS. Kebijakan TTS yang mentargetkan rata-rata pertumbuhan ekonomi sebesar 7 persen untuk mengurangi kemiskinan dan pengangguran sudah dapat dinyatakan tidak tercapai dan gagal (Prasetyo, 2008, 2011). Selama 10 tahun masa pemerintahan Presiden SBY (2004-2014), kemiskinan hanya turun $5,7 \%$ dari $16,7 \%$ menjadi $11 \%$ dan tingkat pengangguran absolut dan relatif walau cenderung turun juga masih tinggi. Nilai Rasio Gini sebagai indeks ketimpangan justru cederung meningkat dari 0,32 menjadi 0,41 artinya semakin timpang. Berdasarkan data dari BPS (Maret 2018), jumlah kemiskinan sebesar 9,82\% dan ditargetkan tahun 2019 menjadi 8,5\%. Rasio Gini per Maret 2018 sebesar 0,39 dan di perkotaan 0,401 serta jumlah pengangguran sebesar 5,13\%. Selama pemerintahan Presiden Jokowi, (2015-2019) pertumbuhan ekonomi ditargetkan rerata sebesar $6 \%$ tetapi belum juga dapat tercapai.

Kewirausahaan adalah pilihan pekerjaan yang semakin lazim di banyak negara (Audretsch, 2009). Kewiraushaan adalah tentang penciptaan pekerjaan dan pertumbuhan ekonomi melalui inovasi (Acs, 2018). Kebijakan yang baik hanya dapat dihasilkan dengan berfokus pada inovas dan pertumbuhan ekonomi yang berorientasi pada kewirausahaan (Acs, 2018). Kebijakan pengembangan kewirausahaan sebagai kekuatan penting dalam menggerakan 


\section{PAIMAN EKO PRASETYO \\ Peran Strategis Kewirausahaan Dalam Mendukung Kebijakan Four Track Strategy Di Indonesia}

ekonomi industri, dan sebagai titik fokus kebijakan pertumbuhan ekonomi, karena bukti yang meningkat menunjukan bahwa perusahaan-perusahaan baru dan kecil berfungsi sebagai mata rantai yang hilang untuk pertumbuhan ekonomi dan penciptaan lapangan kerja (Haltiwanger, 2006; Turik, 2008; Audretsch, 2009; Acs, et al., 2009; Braunerhjelm, 2010; Bergmann, et al. 2014). Keberhasilan wirausahawan baru yang mampu menangkap pasar dan pasar saham memunculkan kesan bahwa kewirausahaan adalah kunci utama untuk membuka pertumbuhan ekonomi dengan mempromosikan perusahaan baru yang inovatif yang mampu meyediakan banyak tenaga kerja dan produk serta layanan yang kompetitif (Bergmann, et al. 2014). Inovasi dan kewirausahaan kini telah dianggap sebagai faktor kunci utama pertumbuhan ekonomi dan kelangsungan hidup ekonomi moderen (Bashir, 2017).

Urgensi pokok masalah dalam artikel ini adalah untuk mengkaji peran strategis kewirausahaan dalam mendukung kebijakan FTS di Indonesia pada era pemerintahan Presiden Joko Widodo (2015-2019), dimana pokok masalah tersebut dapat dirumuskan bagaimana peran strategis kewirausahaan dalam mendorong pertumbuhan ekonomi, mengurangi pengangguran, kemiskinan dan ketimpangan disitribusi pendapatan serta sebagai modal pembangunan ekonomi. Dengan kata lain, apakah peran kewirausahaan mampu mendorong pertumbuhan ekonomi yang selanjutnya mempengaruhi kemiskinan, ketimpangan pendapatan serta meningkatkan kesempatan kerja dan pembangunan ekonomi.

\section{REVIEW LITERATUR}

Joseph Schumpeter seorang Ekonomi Amerika- Austria (1883-1950) telah melakukan kajian peran kewirausahaan dan inovasi sebagai kekuatan pedorong pertumbuhan dan pembangunan ekonomi.
Pada masa ini kebijakan peningkatan peran strategis kewirausahaan dalam mendorong pertumbuhan ekonomi dan pembangunan ekonomi di berbagai negara maju dan berkembang sudah banyak dibahas oleh Karadag (2016), Bonito (2017), Doran (2018) Chen (2018) dan Ace (2018). Karena pentingnya kewirausahaan dan inovasi dalam pembangunan ekonomi maka pada saat ini terdapat index yang disebut sebagai Global Entrepreneurship Indeks (GEI) yang merupakan index penting untuk membantu menilai dan mengevaluasi sikap masyarakat, sumber daya dan infrastruktur yang membentuk ekosistem kewirausahaan di sebuah negara. Karena pentingnya kewirausahaan dalam pembangunan ekonomi , di Amerika telah dibentuk Lembaga kewirausahaan dan pengembangan global sebagai organisasi riset terkemuka di dunia ekonomi untuk memajukan ilmu pengetahuan tentang hubungan antara kewirausahaan, pembangunan ekonomi dan kemakmuran yang bermarkas di Washingtod D.C. yang lebih dikenal dengan sebutan (The GEDI Institute).

\section{The Global Entrepreneurship Index (GEI)}

The Global Entrepreneurship and Development Institute (The GEDI Institute), sebagai lembaga riset terkemuka telah membuat terobosan nilai indek kewirausahaan global sebagai tolak ukur peran strategis kualitas dan dinamika ekosistem kewirausahaan dalam pembangunan di tingkat regional dan nasional yang diberi nama Global Entrepreneurship Index (GEI). Selain itu, ada lembaga asosiasi sebagai tim riset kewirausahaan global atau the Global Entrepreneurship Research Association (GERA). Selanjutnya, GERA telah membuat model proyek dan program konsorsium riset terkemuka yang diberi nama GEM (Global Entrepreneurship Monitor). Selanjutnya, Tim GEM ini bertugas untuk melakukan monitoring dan memahami hubungan antara kewirausahaan dengan pembangunan 


\section{JURNAL OPTIMUM, Volume 10, Nomor 1 Maret 2020}

ekonomi regional, nasional dan global. Kemudian, tim GEM ini memperkenalkan nilai indek baru yang diberi nama GESI (GEM Entrepreneurship Spirit Index). Indeks baru GESI ini didasarkan pada tiga pertanyaan yang jawabanya cukup "ya" atau "tidak" terkait dengan masalah; kesadaran kewirausahaan, peluang atau persepsi dan kemandirian kewirausahaan. Di mana nilai skor indeks GESI tersebut diperoleh berdasarkan data yang diperoleh dari GEM APS (GEM Adult Population Survey). GEM APS ini dirancang untuk mengumpulkan informasi rinci tentang aktivitas kewirausahaan, sikap dan aspirasi responden. Di mana GEM memberikan informasi paling komprehensif dan menawarkan basis data yang berfungsi sebagai dasar untuk peneltian dan publikasi akademik (Acs, 2018; Bosma, 2018; Cheyre, 2018). Selanjutnya, data dari GEM ini lah yang digunakan sebagai sumber dalam analisis pada studi ini.

\section{Keterkaitan antara Kewirausahaan dan Pertumbuhan Ekonomi}

Berbagai penelitian menunjukkan keterkaitan positif antara kewirausahaan dan pertumbuhan ekonomi. Hasil review ini yang menyatakan bahwa kewirausahaan adalah faktor kunci pertumbuhan ekonomi, (Kreft, 2003; Sobel, 2006; Prasetyo, 2008; Thurik, 2009; Audretsch, 2009; Bergmann, 2014; Lundin, 2015; Karadag, 2016; Korez, 2016; Bjørnskov, 2018; Bosma, 2018; Doran, 2018; Ogunlana, 2018). Hasil studi Ogunlana (2018) menemukan kewirausahaan dapat memainkan peran penting dalam mencapai pertumbuhan ekonomi bagi negara untuk mengatasi krisis ekonomi. Ia menegaskan kewirausahaan dapat menghasilkan lapangan kerja, inovasi, meningkatkan produksi, dan diversifikasi sumber pendapatan ekonomi sambil mendorong pengembangan usaha kecil dan menengah di Nigeria.

Korez (2016) telah mengeksplorasi daya saing negara dan kewirausahaan sebagai pendorong pertumbuhan ekonomi. Penelitian tersebut dilakukan pada sampel Negaranegara anggota Eropa Tengah dan Timur (CEE) dari Uni Eropa (UE). Hasil riset empiris (Lundin, 2015) berdasarkan data dari 33 Negara OECD, menunjukkan dukungan kuat dari hubungan positif antara kewirausahaan dan pertumbuhan intensif, serta dukungan kuat untuk hubungan jangka panjang yang positif antara kewirausahaan dan pertumbuhan inklusif. Dengan kata lain, Ia menegaskan bahwa kewirausahaan tidak hanya mempengaruhi pertumbuhan PDB tetapi, juga pertumbuhan inklusif (pendapatan rumah tangga). Sehubungan dengan itu, Bjørnskov (2018) menegaskan bahwa institusi dan kebijakan dapat memoderasi serta menengahi efek kewirausahaan pada pertumbuhan ekonomi dan kinerja lainnya. Ia menjelaskan, ada bukti yang sangat substansial mendukung klaim bahwa aktivitas kewirausahaan memiliki keterkaitan positif dengan konsekuensi ekonomi jangka panjang dalam hal kekayaan, produktivitas, dan pertumbuhan ekonomi.

\section{Keterkaitan antara Kewirausahaan dan Pengangguran}

Riset tentang kebijakan pengembangan kewirausahaan sebagai solusi untuk mengurangi tingkat pengangguran di berbagai negara dilakukan oleh Thurik (2003) Audretsch (2009), Marič (2010), Dilanchiev (2014), Mahadea (2018) dan Kareem (2018). Riset Thurik (2003) menggunakan dasar teori bahwa hubungan antara kewirausahaan dan pengangguran dianalisis menggunakan dua faktor. Faktor pertama adalah efek tarik (Schumpeters effect), factor kedua adalah efek dorongan (refugee' effect or 'shopkeeper efect). Menurut Schumpeter effect, ada hubungan negatif antara kewirausahaan dengan pengangguran, kewirausahaan mampu mengurangi pengangguran sedang menurut refugee effect, pengangguran akan mendorong kewirausahaan, dan sesuai dengan efek Schumpeter kewirausahaan berhubungan negatif dengan pengangguran. Hasil riset 


\section{PAIMAN EKO PRASETYO \\ Peran Strategis Kewirausahaan Dalam Mendukung Kebijakan Four Track Strategy Di Indonesia}

Turik (2003) dan Stel, (2007) menemukan bahwa efek kewirausahaan pada pengangguran tidak berbeda dengan di negara-negara OECD lainnya meskipun tingkat pengangguran di UK dan di Jepang dipengaruhi oleh guncangan eksogen tertentu. Akibatnya, tidak hanya alasan teoritis di atas, tetapi juga ada bukti empiris bahwa sementara pengangguran menyebabkan peningkatan wirausaha, dan wirausaha menyebabkan berkurangnya pengangguran. Fenomena ini juga telah dialami oleh bangsa Indonesia, ketika krisis terjadi pada tahun 1998, jumlah pengguran sangat besar akibat banyak korban PHK (pemutusan hubungan kerja). Pada saat itu, pilihan masyarakat adalah pada bidang usaha kewirausahaan khususnya (UMKM) dan studi lanjut ke tingkat yang lebih tinggi.

Kewirausahaan sebagai solusi masalah pengangguran juga dijelaskan oleh Marič, (2010). Dasar riset Marič dibangun di atas hipotesis yang menyatakan bahwa; di mana ada tingkat pengangguran yang lebih tinggi, maka di situ lebih banyak orang akan transit ke kewirausahaan, dan di mana ada tingkat kewirausahaan yang lebih tinggi akan ada tingkat pengangguran yang lebih rendah. Untuk menguji hipotesis tersebut, digunakan data yang tersedia dari berbagai negara dan mengukur korelasi antara tingkat kewirausahaan dan tingkat pengangguran serta membuat analisis regresi dari kedua nilai tersebut. Haril risetnya menjelaskan bahwa efek hipotesis tersebut semakin lebih jelas dalam jangka panjang daripada proses jangka pendek (Marič, 2010). Sedangkan, hasil riset Dvouletý, (2017) menyatakan bahwa kewirausahaan meningkat di atas tingkat awal setelah dua tahun dan menyarankan untuk mendukung aktivitas kewirausahaan, terutama selama masa pengangguran yang lebih tinggi. Hasil riset Dvouletý, (2017) menyimpulkan bahwa diperlukan waktu hingga dua tahun sebelum efek positif pada pengungkapan kewirausahaan tersebut. Temuan ini memberikan nilai bagi kebijakan strategi peningkatan kewirausahaan di Indonesia pada saat ini dan mendatang.

\section{Linkage between Entrepreneurship and Poverty}

Sejarah dunia menunjukkan bahwa setiap masyarakat menghasilkan masalah sosial kemisikinan-nya sendiri dan berupaya untuk memecahkan masalah tersebut. Salah satu cara untuk mengatasi kemiskinan yang persisten, terutama di minoritas dan sosial masyarakat yang kurang beruntung di Alabama, adalah melalui kewirausahaan. (Starks, 2012). Disimpulkan bahwa ada hubungan yang signifikan antara kewirausahaan dan pengentasan kemiskinan pada tingkat probabilitas 1 persen, (Kareem, 2015). Studi lain menegaskan bahwa ada korelasi positif yang lemah antara pengembangan kewirausahaan dan pengurangan kemiskinan, (Ali, 2013). Sedangkan, hasil riset Hussain (2014), menemukan; inovasi, pendidikan \& pelatihan kewirausahaan, latar belakang keluarga, program dukungan pemerintah, kewirausahaan sosial, partisipasi wanita, karakteristik idividu wirausaha, pemberdayaan pemuda, kolaborasi GUI (pemerintah-universitas-industri), serta partisipasi usaha mikro, kecil menegah (UMKM) adalah kunci dan alat untuk pengembangan kewirausahaan yang merangsang pekerjaan dan pada akhirnya mengurangi kemiskinan.

Hasil riset empiris di Nigeria (Ifeoma, 2018), menyimpulkan bahwa pengembangan kewirausahaan adalah alat utama untuk pengurangan kemiskinan; merangsang lapangan kerja dan pertumbuhan ekonomi di negara-negara berkembang termasuk di Nigeria. Hasil riset (Ogunlana, 2018) juga menyatakan bahwa kewirausahaan memainkan peran penting dalam pembangunan ekonomi di Nigeria, khususnya, selama krisis ekonomi karena kewirausahaan mampu mendorong penciptaan lapangan kerja, mengurangi pengangguran, 
memberantas kemiskinan dan menciptakan nilai. Studi empiris Naminse (2018) menyimpulkan ada hubungan yang signifikan antara kewirausahaan petani dan pengentasan kemiskinan pedesaan di Provinsi Guangxi Cina. Demikian juga hasil studi literature (Lateh, at al., 2018) menyatakan bahwa kewirausahaan sosial dianggap sebagai alat penting dalam pembangunan bangsa dan pengentasan kemiskinan. Hasil studi (Lateh, at al., 2018) juga membenarkan hubungan antara pengembangan kewirausahaan sosial dan pengentasan kemiskinan.

\section{Linkage between Entrepreneurship and Income Inequality}

Kunci utama dan sumber terjadinya ketidakmerataan ekonomi adalah karena diabaikanya peran kewirausahaan (Packard, 2017). Menurut hasil riset Halvarsson, (2018) menunjukkan bahwa kewirausahaan, mempengaruhi distribusi pendapatan menjadi semakin luas. Berbagai studi yang mengungkap hubungan potensial antara kewirausahaan dan ketimpangan pendapatan cenderung berfokus pada ketidakmerataan pendapatan di dalam perusahaan, dan yang paling sering diukur dengan koefisien Gini. Halvarsson (2018) dengan model dekomposisi temuannya menjelaskan bahwa kewirausahaan tidak secara eksklusif menjelaskan perubahan ketimpangan pendapatan, tetapi merupakan faktor yang perlu diamati sebagai salah factor yang mempengaruhi ketimpangan. Hasil studi review literature, hampir sebagian besar menyatakan ada keterkaitan negatif antara peran kewirausahaan dengan ketimpangan distribusi pendapatan. Artinya, peran kewirausahaan mampu membantu mengurangi ketimpangan pendapatan, (Kimhi, 2010; Audretsch, 2014; Chowdhury, at al., 2014; DaCosta, 2017; Packard, 2017; dan Halvarsson, 2018). Kecuali, Isenberg (2014) menyatakan bahwa kewirausahaan selalu mengarah pada ketidakmerataan pendapatan. Karena para kewirausahaan yang sukses "meledak ke pasar dan menghasilkan kekayaan yang luar biasa" dan yang paling berhasil akan "mengganggu" industri dan model bisnis yang mapan, sehingga meyebabkan ketidakmerataan. Di mana kewirausahaan yang sukses selalu memperparah ketidaksetaraan lokal di Cina. Namun demikian, hasil riset Isenberg (2014) tersebut dibantah oleh Li, 2015; dan DaCosta, 2017. Menurut Li (2015), ada keterkaitan negatif antara kegiatan kewirausahaan dengan ketimpangan pendapatan. Li menegaskan bahwa membina kewirausahaan justru akan menjadi "peningkatan kesejahteraan" di Cina. DaCosta (2017) juga menyiratkan ada korelasi negatif antara disparitas pendapatan dengan kewirausahaan. Hasil riset DaCosta (2017) menjelaskan bahwa, memang di Cina terjadi tingkat pendapatan rumah tangga nonkewirausahaan cederung lebih merata daripada rumah tangga kewirausahaan, namun tetap menunjukkan korelasi negatif antara kewirausahaan dengan ketimpangan pendapatan.

\section{Keterkaitan antara Kewirausahaan danPerkembangan Ekonomi}

Studi yang membahas keterkaitan antara kewirausahaan dengan pembangunan ekonomi belum banyak ditemukan seperti pada keterkaitan antara kewirausahaan dengan pertumbuhan ekonomi. Menurut pandangan Schumpeterian, proses kewirausahaan merupakan salah satu faktor kunci dalam pembangunan ekonomi dari suatu negara atau wilayah (Toma, 2014). Peran positif kewirausahaan terhadap pembangunan ekonomi belum solid (Naude, 2013; Audretsch, 2015; Bjørnskov, 2017; Dvouletý, 2018). Para pembuat kebijakan telah mengidentifikasi hubungan antara kewirausahaan dan pembangunan ekonomi. Namun sedikit yang diketahui tentang bagaimana hubungan ini bervariasi dari waktu ke waktu di kota-kota dengan ukuran pasar yang berbeda (Audretsch, 2015). Menurut Toma (2014) kewirausahaan memainkan 


\section{PAIMAN EKO PRASETYO \\ Peran Strategis Kewirausahaan Dalam Mendukung Kebijakan Four Track Strategy Di Indonesia}

peran kunci dalam pembangunan ekonomi. Toma (2014) menegaskan bahwa kewirausahaan secara luas diakui baik oleh para akademisi dan praktisi sebagai faktor fundamental ekonomi pembangunan di seluruh dunia. Namun, kewirausahaan dapat mempengaruhi pembangunan ekonomi secara positif maupun negatif.

Hubungan antara kewirausahaan dan pembangunan ekonomi (Is It U-Shaped) adalah berbentuk $U$ terbalik (Wennekers, 2010; Naude, 2013). Wennekers (2010) menjelaskan berbentuk $U$ tersebut karena adanya tingkat yang lebih tinggi dari aktivitas kewirausahaan di Negara berpenghasilan rendah daripada di Negara-negara berpenghasilan menengah. Selanjutnya, Wennekers (2010) menegaskan bahwa kewirausahaan telah menjadi isu kebijakan utama. Argumentasinya bahwa wawasan dalam hubungan antara kewirausahaan dan pembangunan ekonomi negara adalah penting bagi pembuat kebijakan karena berhubungan dengan menyediakannya cara untuk usaha mereka. Wawasan kebijakan tersebut dapat mendorong minimal dua revolusi yang sangat berharga. Kedua revolusi tersebut adalah; (1) kebangkitan self-employment, yang dapat meningkatkan fleksibilitas dan produktivitas sistem ekonomi dan berkontribusi pada kepuasan kerja, (2) adanya tren ke atas yang inovatif yang penting untuk daya saing, peningkatan pertumbuhan ekonomi dan penciptaan lapangan kerja baru. Ia menyarankan agar pembuat kebijakan di negara maju mengerti tentang kedua revolusi tersebut, mengenali determinan dan implikasi kewirausahaan dan melakukan kebijakan yang sesuai.

\section{METODE PENELITIAN}

Riset ini dilakukan dengan pendekatan studi literature. Sumber data yang digunakan adalah dari Global Entrepreneurship Monitor (GEM) dan Badan Pusat Statistik (BPS) serta dari berbagai riset peneliti sebelumnya.
Tujuan dari studi ini adalah melihat keterkaitan kewirausahaan dengan pertumbuhan ekonomi, pengangguran, kemiskinan, ketimpangan pendapatan dan pembangunan ekonomi. Metode analisis yang digunakan adalah metode analisis deskriptif.

\section{HASIL PENELITIAN DAN PEMBAHASAN}

Berdasarkan data hasil riset The GEDI Institute dan GERA, yang mengukur peringkat indeks kewirausahaan global, pada tahun 2018 ada sejumlah 137 negara. Pada gambar-1, nampak bahwa nilai skor indeks GESI dan nilai GEDI ranking Indonesia sejak tahun 2014 hingga 2018 cenderung mengalami penurunan. Pada tahun 2014, nilai skor GESI 34,2 dan nilai GEDI ranking berada pada posisi 67 . Sedangkan, pada tahun 2018 nilai skor GESI menjadi hanya sebesar 20,7 dan nilai GEDI ranking ada pada posisi 94 dari 137 negara yang di monitoring oleh riset GEM (Acs, 2018; Cheyre, 2018). Fenomena penurunan ini berarti menunjukkan peran kewirausahaan terhadap pembangunan ekonomi di Indonesia cenderung menurun karena kewirausahaan semakin tidak mampu menciptakan pekerjaan sendiri (selfemployment) dan menghasilkan pertumbuhan ekonomi yang lebih baik hal tersebut menunjukkan bahwa peran kewirausahaan semakin menurun dalam pengurangan kemiskinan dan ketimpangan pendapatan di Indonesia. Dengan kata lain, model kebijakan FTS belum berhasil seperti yang diharapkan.

Ada beberapa faktor utama yang diduga sebagai penyebab belum berhasilnya model kebijakan FTS yaitu (1) belum dirumuskannya dengan baik dan benar strategi kewirausahaan nasional, (2) kebijakan regulasi yang telah dilakukan belum optimal, (3) masih rendahnya program peningkatan pendidikan dan pelatihan kewirausahaan, (4) masih rendahnya alih teknologi dan inovasi, (5) masih lemahnya peningkatan akses inklusi keuangan masyarakat, serta (6) sosialisasi dan 
promosi kesadaran jejaring kewirausahaan masih rendah.

Berdasarkan data dari GEM (2018) nilai skor GESI dan posisi GEDI rangking Indonesia menurun. Pada tahun 2018 terdapat 10 negara yang mengalami nilai skor GESI menurun secara urut dari nomor satu sampai dengan sepuluh yakni; Saudi Arabia, Lebanon, Indonesia, Polandia, Peru, Kazakhstan, United Arab Emirates, Sweden, Colombia, dan Netherlands, (Cheyre, 2018).

Gambar-1 juga menunjukkan ada hubungan positif antara menurunnya peran kewirausahaan dengan kesulitan membaiknya proses pencapaian pembangunan ekonomi di Indonesia. Yang perlu dilakukan adalah membangkitkan dan mengembangkan jiwa kewirausahaan serta dirumuskannya kebijakan yang baik dan benar tentang kewirausahaan nasional yang berbasis pada potensi dan keunggualan kearifan lokal serta berorientasi ekspor.

\section{Gambar 1.}

Peran Kewirausahaan Dalam Pembangunan Ekonomi Indonesia

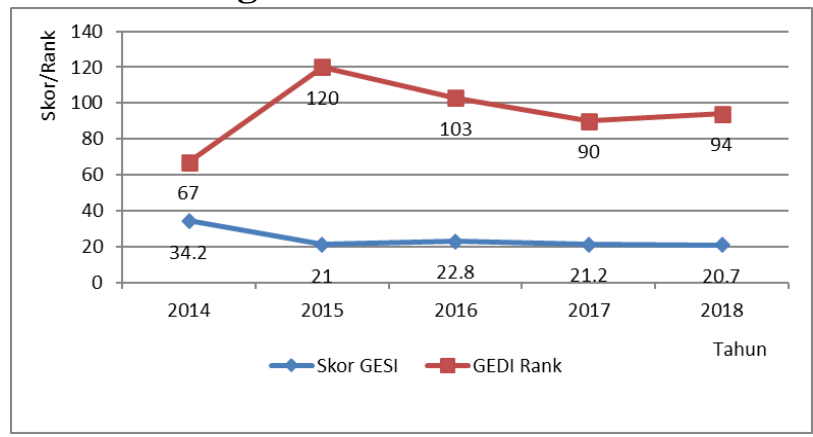

Sumber: Global Entrepreneurship Index, (2014-2018)

Pada tahun 2018, posisi GEDI rangking satu dan rangking dua dengan nilai skor GESI tertinggi pertama adalah Negara United States dan tertinggi kedua Switzerland, dengan masing-masing skor GESI sebesar 83,6 dan 80,4. Sedangkan, dua Negara dengan GEDI rangking terbawah dan skor nilai GESI terrendah, yakni pada posisi 136 adalah Negara Mauritania dengan nilai skor GESI sebesar 10,9 dan pada posisi GEDI ranking ke
137 dengan skor GESI sebesar 9,0 adalah Negara Chad (Acs, 2018). Jika dilihat lebih rinci berdasarkan data dari GEI dan GEM (Acs, 2018; Cheyre, 2018), peran kewirausahaan terhadap pembangunan ekonomi di Indonesia cederung terus menurun (gambar-1). Nilai skor GESI Indonesia masing-masing sejak tahun $2014(34,2)$ tahun 2015 (21,0), tahun $2016(22,8)$, tahun 2017 (21,2) dan tahun 2018 (20,7). Sedangkan, GEDI rangking masing-masing pada tahun 2014 (67), tahun 2015 (120), tahun 2016 (103), tahun 2017 (90) dan tahun 2018 (94). Untuk posisi skor GESI Indonesia pada tahun 2018 adalah sama dengan Negara Bosnia and Herzegovina dengan nilai skor GESI 20.7 serta Bosnia and Herzegovina berada pada GEDI rangking ke 95 (Acs, 2018; Cheyre, 2018).

Selanjutnya, ketika nilai skor baru GESI dilihat berdasarkan GEM APS diperoleh, maka dapat diketahui ketentuan peringkat dari tertinggi hingga terendah. Lima negara peringkat teratas dalam indeks ini adalah semua negara yang dikendalikan oleh efisiensi, dan lima negara dengan peringkat terendah adalah negara yang didorong inovasi. Namun, hasil riset monitoring GEM (Cheyre, 2018) ada tiga dari 10 negara teratas didorong oleh inovasi dan empat dari 10 negara paling bawah didorong oleh efisiensi. Tiga dari empat negara yang digerakkan oleh faktor yang memiliki nilai skor positif dalam indeks. Selanjutnya, Cheyre (2018) menjelaskan bahwa negara-negara dengan jiwa kewirausahaan tinggi dan rendah dapat menjadi bagian dari salah satu tahap proses pembangunan ekonomi. Negara-negara pengelompokan sesuai dengan tahap pengembangan ekonomi yang menunjukkan dominasi semangat kewirausahaan di antara ekonomi berbasis efisiensi. Menurut data hasil riset GEM (2018) perekonomian Indonesia cenderung baru digerakan oleh faktor efisiensi (efficiency-driven economies), dan belum digerakan oleh faktor inovasi (innovationdriven economies). Bedasarkan pada gambar- 


\section{PAIMAN EKO PRASETYO \\ Peran Strategis Kewirausahaan Dalam Mendukung Kebijakan Four Track Strategy Di Indonesia}

2, jika tahap pembangunan di bagi menjadi tiga tahapan (stage) yakni; (stage-1; didorong oleh faktor produksi dan transmisi yang digerakan menuju efisiensi), (stage-2; didorong oleh efisiensi dan transmisi yang digerakan menuju inovasi) dan (stage-3 didorong oleh inovasi), maka peran kewirausahaan dalam perekonomian Indonesia baru berada di bagian bawah pada stage- 2 .

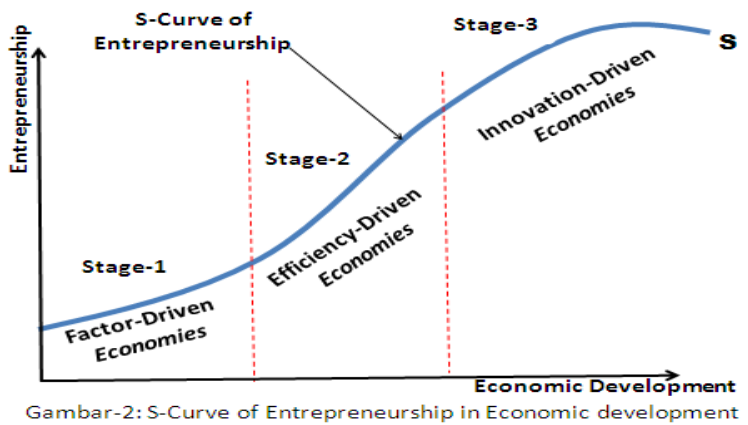

Jika didasarkan pada ketentuan skor nilai GESI dari GEM APS, maka secara empiris hasil riset untuk jenis pelaku kewirausahaan pada kluster (Micro Enterprises dan Small Entreprise) di Indonesia dapat dinyatakan lebih didorong oleh faktor; kreativitas, skill dan inovasi (Prasetyo, 2008, 2017a; Purba, 2018; Pudaka, 2018). Sedangkan, untuk jenis kewirausahaan pada kluster (Medium Enterprises dan Large Enterprises) justru cenderung baru didorong oleh faktor efisiensi teknis, teknologi dan kolaborasi (Prasetyo, 2010, 2014, 2017b.; Suwardi, 2018; Zia, 2018). Argumentasi yang mendasari dapat terjadinya fenomena tersebut adalah; karena untuk kluster usaha mikro dan kecil (micro and small entreprises) di Indonesia bisa tumbuh dan besar lebih disebabkan oleh kreatifitas dan kerja kerasnya serta sedikit inovasi. Sedangkan, pada kluster usaha menengah dan besar (medium and large enterpreises) dapat tumbuh dan besar karena adanya koneksitas dan fasilitas yang diberikan negara serta adanya kolaborasi.

Hal yang dapat dilakukan Indonesia untuk meningkatakan keberhasilan FTS adalah dengan menentukan arah kebijakan pembangunan jangka pendek dan jangka panjang dalam bidang ekonomi dan harus secara konsisten meningkatkan kapasitas masyarakat dalam bidang kewirausahaan dan kapasitas industri berorientasi ekspor yang berbasis pada potensi dan kearifan lokal. Kebijakan strategi peningkatan kapasitas kewirausahaan dan industri dapat dilakukan dengan berbagai macam cara yakni pendidikan dan pelatihan, inovasi, kolaborasi, pemberdayaan, serta partisipasi aktif usaha mikro, kecil dan menegah yang berbasis potensi dan kearifan lokal. Selanjutnya, strategi kebijakan pengembangan kewirausahaan yang kreatif dan inovatif serta berbasis potensi dan kearifan lokal tersebut harus terus-menerus didorong dan diarahkan mejadi pelaku ekonomi mandiri yang semakin berbasis iptek yang efisien, efektif, adaptif, produktif, serta berdaya saing tinggi dan berkelanjutan agar srategi kebijakan FTS dapat berhasil dan misi dan visi pada RPJPM dan RPJPN di Indonesia yang pada tahun 2025 ingin menjadi Negara mandiri, maju, adil dan makmur juga dapat tercapai.

KESIMPULAN DAN REKOMENDASI

Artikel ini telah mendiskripsikan kerangka konseptual yang didukung data hasil riset empiris tentang stategis kebijakan peningkatan peran strategis kewirausahaan sebagai kunci utama dalam mendorong peningkatan kapasitas pertumbuhan ekonomi untuk mengatasi masalah tingginya; penganguran, kemiskinan dan ketimpangan pendapatan serta menuju proses pembangunan ekonomi yang lebih bermanfaat secara riil dan berkelanjutan. Kurva S tersebut menunjukkan seberapa besar dan seberapa cepat peran strategis kewirausahaan produktif dalam perekonomian di Indonesia. Kurva $\mathrm{S}$ tersebut juga menunjukkan ada korelasi yang positif antara kewirausahaan produktif dengan keberhasilan dalam proses pencapaian pembangunan ekonomi di Indonesia. Artikel 
konseptual ini telah didasarkan pada kajian teoritis dan didukung data empiris, sehingga secara ilmiah cukup komprehensif dan dianggap respresentatif. Namun demikian, artikel ini hanyalah sebuah konseptual yang proporsi risetnya tentu masih harus terus diuji secara empiris dengan cakupan wilayah riset yang lebih luas dan kompleks. Direkomendasikan agar riset-riset ke depan lebih spesifik serta tetap dengan jangkauan wilayah yang lebih luas dan banyak.

\section{DAFTAR PUSTAKA}

Ács. Z.J., Szerb, L., \& Lloyd, A. (2018). The Global Entrepreneurship Index, The Global Entrepreneurship and Development Institute, Washington, D.C., USA.

Acs, ZJ., Audretsch, DB., \& Strom, RJ. (2009). Enrepreneurship, Growth, and Public Policy, Cambridge University Press. www.cambridge.org

Ali Yassin SA., \& Ali, AH. (2013). Entrepreneurship Development and Poverty Reduction: Empirical Survey from Somalia, American International Journal of Social Science. Vol. 2 No. 3, pg. 108-113.

Audretsch, DB., Belitski, M., and Desai, S. (2015). Entrepreneurship and economic development in cities. Annals of Regional Sciences, Urban Entrepreneurship and Economic Development 55 (1). pp. 33-60. ISSN 1432-0592

Audretsch, DB., Lehmann EE., \& Keilbach, M. (2009). Entrepreneurship and Economic Growth, Research Paper No. 47, UNU-WIDER and UNU-MERIT Research,

Bashir, HA., \& Akhtar, A. (2017). The Role of Innovative Entrepreneurship in Economic Development: A Study of G20 Countries, Management Studies and Economic Systems (MSES), 3 (2), pg. 91-100.
Bjørnskov, C., \& Foss, Nj. (2018). Institutions, Entrepreneurship, and Economic Growth: What Do We Know and What Do We Still Need to Know, Academy of Management Perspectives, 2016, Vol. 30, No. 3, 292-315.

Bonito, JDM., at al. (2017). Do Entrepreneurship and Economic Growth Affect Poverty, Income Inequality and Economic Development, Review of Integrative Business and Economics Research, Vol. 6, no. 1, pp.33-43.

Bosma, N., Schøtt, T., Terjesen, S., \& Kew, P. (2018). Global Entrepreneurship Monitor, Special Topic Report Social Entrepreneurship, Founding and Sponsoring Institutions, United Kindom: LBS.

Braunerhjelm, P. (2010). Entrepreneurship, Innovation and Economic Growth: Past Experiences, Current Knowledge and Policy Implications, Working Paper, Research Network Debate, Swedish Entrepreneurship Forum.

Chen, FW., at al. (2018). The Influence of Entrepreneurship and Social Networks on Economic Growth-From a Sustainable Innovation Perspective, Sustainability, $\quad 10, \quad 2510$; doi:10.3390/su10072510.

Cheyre, H., Menipaz, E.E. (2018). Global Entrepreneurship Monitor, Global Entrepreneurship Research Association (GERA), Global Report, 2017-2018

Dilanchiev, A. (2014). Relationship between Entrepreneurship and Unemployment: The Case of Georgia, Journal of Social Sciences, Volume 3, Issue 2, pg. 5-9.

Doran, J., McCarthy, N., and O'Connor, M. (2018). The role of entrepreneurship in stimulating economic growth in developed and developing countries, Cogent Economics \& Finance, 6: 1442093, open asses https://doi.org/10.1080/23322039.

Haltiwanger, John. (2006). Entrepreneurship and Job Growth, Paper presented at the 


\section{PAIMAN EKO PRASETYO}

\section{Peran Strategis Kewirausahaan Dalam Mendukung Kebijakan Four Track Strategy Di \\ Indonesia}

Conference on "Entrepreneurship and

Economic Growth", (Ringberg Castle),

Rottach Egern, 8-9 May 2006.

Hussain, MD., \& Bhuiyan, AB. (2014).

Entrepreneurship Development And

Poverty Alleviation: An Empirical

Review, Journal of Asian Scientific

Research, Vo/ 4 No. 10, pg.558-573.

Ifeoma, AR., Purity, NO., and Yusuf, AE. (2018). Effect of Entrepreneurship Development on Poverty Alleviation in Nigeria, IOSR Journal of Business and Management (IOSR-JBM, Volume 20, Issue 2. Ver. X, Pg. 80-87. www.iosrjournals.org

Isenberg, D. (2014). Entrepreneurship always leads to inequality. Harvard Business Review.

Retrieved, https://hbr.org/2014/03/entrepreneurship -always-leads-to-inequality.

Karadag, H. (2016). The Role of SMEs and Entrepreneurship on Economic Growth in Emerging Economies within the PostCrisis Era: an Analysis from Turkey, Journal of Small Business and Entrepreneurship Development, Vol. 4, No. 1, pp. 22-31

Kareem, B. (2018). Impact of Entrepreneurship on Unemployment/Underemployment Rate in Nigeria: Islamic Perspective, Specialty Journal of Accounting and Economics, Vol, 4 (1). Pg. 12-18

Kareem, RO. (2015). Impact of Entrepreneurship on Poverty Alleviation, Journal of Business Administration and Education, Volume 7, Number 1, pg. 1-16

Kimhi, A. (2010). Entrepreneurship and income inequality in southern Ethiopia, Small Business Economics, 34(1), 8191.

Korez RV., and Tominc, P. (2016). Competitiveness, Entrepreneurship and Economic Growth, Competitiveness of CEE Economies and Businesses, Springer International Publishing
Switzerland, University of Maribor, Maribor, Slovenia

Kreft, SF. \& Sobel, RS. (2003). Public Policy, Entrepreneurship, and Economic Growth, J.E.L. classification: H7, O1, J0

Lateh, at al., (2018). Social Entrepreneurship Development and Poverty Alleviation-A Literature Review, MAYFEB Journal of Business and Management, Vol 2, Pg. 1-11

Lundin, JN. (2015). Entrepreneurship and Economic Growth: Evidence from GEM Data, Schoolof Economics and Management, Lund University.

Mahadea, D., \& Kaseeram, I. (2018). Impact of unemployment and income on entrepreneurship in post-apartheid South Africa: 1994-2015, The Southern African Journal of Entrepreneurship and Small Business Management, 10(1), pg 1-9.

Marič, M., Mitja Jeraj, M., \& Žnidaršič, J. (2010). Entrepreneurship as a solution to the unemployment problem = Preduzetništvo kao odgovor na problem nezaposlenosti, Škola biznisa, Broj 2. https://www.researchgate.net/publicatio $\mathrm{n} / 269696078$

Naminse, EY., Zhuang J. (2018). Does farmer entrepreneurship alleviate rural poverty in China? Evidence from Guangxi Province, Research Article PLOS ONE, open access article https://doi.org/10.1371/journal.pone.019 4912

Naudé W. (2013). Entrepreneurship and Economic Development: Theory, Evidence and Policy, IZA Discussion Paper No. 7507

Ogunlana, F. (2018). The Role Of Entrepreneurship As The Driver Of Economic Growth, Thesis, Centria University Of Applied Sciences, Business Management

Prasetyo, PE. (2008). The Quality Of Growth: Peran Teknologi Dan Investasi Human 
Capital Sebagai Pemacu Pertumbuhan Ekonomi Berkualitas, Jurnal Ekonomi dan Kebijakan, JEJAK, Vol. 1, No. 1, Hal. 1-14.

Prasetyo, Pe. (2010). Struktur dan Kinerja Industri Besi dan Baja Indonesia Tidak Sekuat dan Sekokoh Namanya, JEJAK, Vol. 3, No. 1, Hal. 12-27.

Prasetyo, PE. (2011). Deindustrialisasi Sebuah Ancaman Kegagalan Triple Track Strategy Pembangunan di Indonesia, Jurnal Ekonomi dan Kebijakan, Vol. 4(1), pg. 1-13.

Prasetyo, PE. (2014). Economic Policy Impact on Competitiveness and Efficiency of Textile Industry in Central Java, Economic Journal of Emerging Market, Vol. 6(2) p. 85-95.

Prasetyo, PE. (2017a). Standarisasi dan Komersialisasi Produk Industri Kreatif dalam Mendukung Pertumbuhan Ekonomi Daerah, Prosiding Seminar Nasional Multidisiplin Ilmu \& Call Paper, Sendu_U3. Juli, Semarang: Unisbank.

Prasetyo, PE. (2017b). Productivity of Textile Industry and Textile Products in Central Java. Jurnal Ekonomi dan Kebijakan, JEJAK, Vol. 10 (2) pg. 57-72.

Prasetyo, PE. (2019). Role of Entrepreneurial Culture as the Driver of Economic Growth, International Journal of Economics and Financial Issues, 9(3), 237-243.

Pudaka, DL., Rusdarti., Prasetyo, PE. (2018). Efficency Analysis of Rice Production and Farmers' Income in Sengah Temila District Landak Regency, Journal of Economic Education, Vol. 7, No. 1, pg. 31-38

Purba, SL., \& Prasetyo, PE. (2018). Analisis Faktor Produksi terhadap Daya Saing Batik Semarangan, Economics Development Analysis Journal, Volome 7, Nomor 3, Halaman 260-265.

Sobel, RS., \& Hall, JC. (2006). Public Policy and Entrepreneurship, Supporting
Regional Economic Development through Analysis and Education, Technical Report, 06-0717, The University of Kansas

Stel, AV., Thurik, R., Verheul, I., \& Baljeu L. (2007). The Relationship between Entrepreneurship and Unemployment in Japan, discussion papers can be downloaded at http://www.tinbergen.nl. version $\mathrm{v} 9$ prepared for ISBJ.

Thurik, R. (2009). Entrepreneurship, Economic Growth and Policy in Emerging Economies, Research Paper, No.12, UNU World Institute for Development Economics Research (UNU-WIDER), publications@wider.unu.edu

Thurik, R. (2003). Entrepreneurship and Unemployment in the UK, Scottish Journal of Political Economy, Vol. 50, No. 3, pg. 264-290.

Wennekers, S., Stel, AV., Carree, M., and Thurik, R. (2010). The Relationship between Entrepreneurship and Economic Development: Is It U-Shaped, Foundations and Trends in Entrepreneurship, Vol. 6, No. 3, pg. $167-237$ 